\title{
Avaliação do possível efeito tóxico de um alcano semifluorinado de uso of talmológico sobre cultura de células Vero
}

\author{
Assessment of the possible toxic effect of a semifluorinated alkane on Vero cell culture
}

\author{
Paulo Estacia ${ }^{1}$ \\ Arnaldo Rodrigues Santos Jr. ${ }^{2}$ \\ Selma Candelária Genari ${ }^{2}$
}

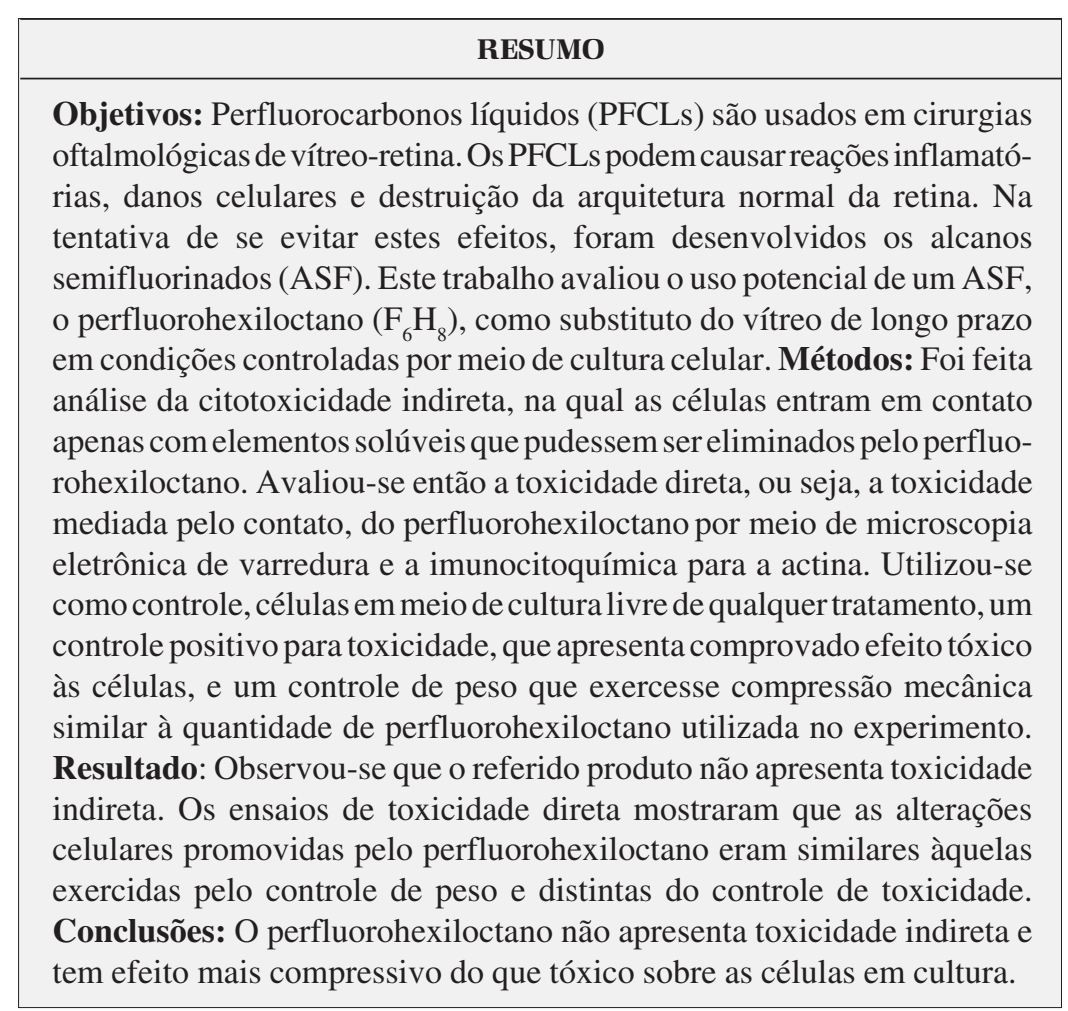

Descritores: Fluorocarbonetos/toxicidade; Cultura de células; Procedimentos cirúrgicos oftalmológicos

\section{INTRODUÇÃOO}

As cirurgias oftalmológicas vítreo-retinianas tiveram grande desenvolvimento com a técnica da vitrectomia, que possibilitou ampla substituição do gel vítreo e manipulação da retina, fornecendo uma opção de tratamento eficiente para reaplicar a retina ao seu leito normal, permitindo manter sua nutrição e capacidade funcional. Este objetivo nem sempre é fácil de ser conseguido, devido ao processo de proliferação fibrosa e conseqüente tração que tende a manter a retina descolada.

O uso dos perfluorocarbonos líquidos (PFCLs) há alguns anos na oftalmologia como ferramenta para devolver a retina a sua posição anatômica de maneira menos traumática, facilitou grandemente a cirurgia de vítreo-retina. A 
maior gravidade específica destes líquidos promove uma estabilização hidrocinética da retina durante a cirurgia, deslocando o líquido sub-retiniano ${ }^{(1)}$. Estas substâncias são empregadas não apenas como ferramenta intra-operatória, mas também como agentes tamponantes intra-oculares (em estudo), que inseridos durante o ato cirúrgico para posicionar a retina, permaneçam o tempo pós-operatório necessário até que se desenvolva uma adesão retiniana que impeça seu redescolamento.

Os perfluorocarbonos têm aplicação numa ampla variedade de condições cirúrgicas desde 1989, quando inicialmente foram usados no manuseio de rupturas gigantes de retina ${ }^{(2)}$. Outros usos incluem casos complicados de descolamento de retina $^{(3-4)}$, vitreoretinopatia diabética ${ }^{(5)}$ e controle de hemorragias vítreas transoperatórias ${ }^{(6)}$. Os PFCLs são eficientes em manter a retina colada, em descolamentos de retina induzidos experimentalmente ${ }^{(7)}$.

Entre os PFCLs usados em oftalmologia temos o perfluoroctano, o perfluorodecalin, a perfluorotributilamina e o perfluorperhidrofenantreno, todos com grande capacidade de transportar e liberar tanto oxigênio $\left(\mathrm{O}_{2}\right)$ como gás carbônico $\left(\mathrm{CO}_{2}\right)$. O perfluoroctano é o mais usado no meio oftalmológico e apresenta melhor visibilidade do menisco formado na interface entre ele e a solução salina balanceada usada na cirurgia ${ }^{(8)}$. Os diferentes PFCLs são eficientes para reaplicar a retina ${ }^{(7)}$ e a decisão sobre qual perfluorocarbono usar vai se basear em uma série de considerações, como experiência do cirurgião, disponibilidade e custo $^{(9)}$.

Alguns autores afirmam que os PFCLs deixados nos olhos dos pacientes após a cirurgia para atuarem como agentes tamponantes podem causar danos celulares ${ }^{(10)}$ e reações inflamatórias como compressão e destruição da arquitetura normal da retina com sua desorganização, alterações degenerativas dos fotoreceptores, ativação dos macrófagos na retina e à redução no número de células ${ }^{(11-13)}$. Entretanto não ficou claro se esses achados deveriam ser atribuídos a danos tóxicos ou mecânicos, observando-se um efeito progressivo proporcional ao tempo de contato dessa substância com a retina ${ }^{(12,14)}$.

Devido à limitação do uso dos PFCLs como substituto do vítreo de longo prazo-decorrente do efeito compressivo muito intenso e do discutível efeito tóxico-novos produtos foram lançados no mercado com este objetivo. São os mais recentes desenvolvimentos dos perfluorocarbonos líquidos. São chamados de "alcanos semifluorinados" (ASF) e consistem da união de um perfluorocarbono com um hidrogencarbono, o que diminui a porção fluorinada na cadeia molecular levando a uma menor densidade ${ }^{(15-16)}$.

Um dos ASF de uso oftalmológico estudados é o perfluorohexiloctano $\left(\mathrm{F}_{6} \mathrm{H}_{8}\right)$. Como os outros PFCLs, os ASFs são límpidos, com índice de refração que varia entre 1,30 a 1,34, portanto próximo ao da água $(1,33)$, o que é desejável a uma substância que deve ficar um maior tempo no olho, até que aconteça a adesão da retina ao seu leito, pois acarretaria uma mínima alteração do poder de refração ocular pós-operatório. Os ASF são solúveis em PFCL, hidrocarbonos e óleo de silicone $^{(17)}$ e tem baixa viscosidade como os PFCL mantendo, portanto as características destes de fácil introdução e remoção do olho através de cânulas de diâmetro pequeno e tendência de se dispersar em pequenas bolhas.

A característica do $\mathrm{F}_{6} \mathrm{H}_{8}$ de ter menor gravidade específica, quando comparado com outros PFCLs, permitiria seu uso pósoperatório como agente tamponante, mantendo a retina na posição desejada, teoricamente com menor risco de dano celu$\operatorname{lar}^{(18)}$. Estudos com o perfluorohexiloctano como substituto do vítreo em olhos de coelhos não mostrou alterações retinianas importantes na microscopia ótica e eletrônica ${ }^{(19)}$ e a experiência clínica com o $\mathrm{F}_{6} \mathrm{H}_{8}$, embora limitada, mostra respostas distintas quanto ao dano retiniano e resposta inflamatória, conforme diferentes trabalhos ${ }^{(20-22)}$. Apesar desses achados iniciais, e devido ao fato do $\mathrm{F}_{6} \mathrm{H}_{8}$ ser um produto novo, estudos referentes a citotoxicidade desse composto são necessários para comprovar a sua segurança. Nesse sentido, nos propomos a avaliar o possível efeito tóxico do $\mathrm{F}_{6} \mathrm{H}_{8}$ em condições isoladas e controladas que somente a cultura celular poderia propiciar. Comparamos os possíveis efeitos do $\mathrm{F}_{6} \mathrm{H}_{8}$ com um controle de peso proporcional ao exercido por ele sobre as células, um controle de toxicidade e uma situação onde as células cresceram livres de qualquer tratamento.

\section{MÉTODOS}

\section{Manutenção das células em cultura}

Neste trabalho foram utilizadas células Vero, uma linhagem celular fibroblástica estabelecida a partir de células renais do macaco verde africano (Cercopithecus aethiops). Estas células são provenientes do Instituto Adolfo Lutz, SP e foram mantidas em meio Ham-F10 (Sigma) com 10\% de soro fetal bovino (SFB, Nutricell) a $37^{\circ} \mathrm{C}$. As trocas de meio foram feitas sempre que ocorresse acidificação do mesmo, e os repiques foram periodicamente efetuados na medida que ocorresse a confluência do tapete celular.

\section{Perfluorohexiloctano $\left(\mathrm{F}_{6} \mathrm{H}_{8}\right)$}

O perfluorohexiloctano (Geuder AG) utilizado neste estudo apresenta as seguintes características químicas: fórmula molecular empírica $\mathrm{C}_{14} \mathrm{~F}_{13} \mathrm{H}_{17}$, fórmula resumida $\mathrm{F}_{6} \mathrm{H}_{8}\left(\right.$ Geuder $\left.^{\circledR}\right)$, peso molecular 432, densidade $1,35 \mathrm{~g} / \mathrm{ml}$, tensão superficial de $21(\mathrm{mN} / \mathrm{m})$, índice de refração 1,34, viscosidade 3,2 (centistoke, a $25^{\circ} \mathrm{C}$ ) e ponto de ebulição de $223^{\circ} \mathrm{C}$. Quando utilizado no meio de cultivo era adicionado lentamente, para evitar a formação de pequenas bolhas.

\section{Teste de citotoxicidade indireta}

Os extratos de $\mathrm{F}_{6} \mathrm{H}_{8}$ foram obtidos colocando-se estes materiais na concentração de $2 \mathrm{~g} / \mathrm{ml}$ de meio Ham F-10 (Sigma) com $10 \% \mathrm{SFB}$ a $37^{\circ} \mathrm{C}$ por 48 horas sem agitação. Depois de transcorrido esse período, o meio foi recolhido, e o $\mathrm{F}_{6} \mathrm{H}_{8}$ presente no mesmo foi descartado. Desta forma pôde ser avaliado o possível efeito de substâncias liberadas pelo $\mathrm{F}_{6} \mathrm{H}_{8}$ que poderiam estar presentes no meio de cultura. $\mathrm{O}$ teste de citotoxici- 
dade indireta e obtenção dos extratos foi delineado de acordo com recomendações internacionais ${ }^{(21)}$.

\section{Análise quantitativa dos extratos sobre as culturas celulares}

Para a análise quantitativa dos extratos sobre as culturas celulares utilizamos o método descrito por Murakami et $\mathrm{al}^{(22)}$. Resumidamente, $100 \mu \mathrm{l}$ de uma suspensão de células Vero contendo 1,0 x $10^{6}$ células/ml em meio Ham-F10 com $10 \%$ de SFB foram inoculadas em uma placa de cultura com 96 poços (Corning $^{\circledR}$, Cambridge, MA, USA) e cultivadas por $12 \mathrm{~h}$ nessas condições a $37^{\circ} \mathrm{C}$. Após este período de incubação o meio de cultivo foi removido e foi adicionado a cada poço $100 \mu 1$ de meio novo com os extratos de $\mathrm{F}_{6} \mathrm{H}_{8}$. Após 12 horas de incubação a $37^{\circ} \mathrm{C}$ os extratos foram removidos e as células foram lavadas com 0,1 ml de tampão fosfato salino 0,1 M (PBS) em pH 7,4 a $37^{\circ} \mathrm{C}$, fixadas em formalina $10 \%$ por 15 minutos, lavadas em PBS pelo mesmo tempo e coradas por cristal violeta $0,05 \%$ (em metanol 20\%) por 15 minutos. As amostras foram então lavadas duas vezes com PBS por 30 minutos e incubados com citrato de sódio a $0,1 \mathrm{M}$ (em etanol $50 \%$ com $\mathrm{pH} 4,2$ ) pelo mesmo período. A placa com as células remanescentes foi lida em um leitor de microplacas Multiskan Bichromatic ${ }^{\circledR}$ Versão 1,06, no comprimento de onda de 540 nanômetros. Foi usado como controle positivo, ou seja, sem efeito citotóxico, um extrato do material da própria placa de cultura (polipropileno). Em todos os experimentos foi usado $n=16$. Para análise estatística foi efetuada a análise da variância dos resultados obtidos (One-Way ANOVA) com nível de significância de 0,05 .

\section{Teste de citotoxicidade direta}

A análise de citotoxicidade direta consiste na avaliação dos possíveis efeitos tóxicos do $\mathrm{F}_{6} \mathrm{H}_{8}$ em contato direto com as culturas de células Vero. Com esse objetivo, $1 \mathrm{ml}$ de suspensão de células Vero em meio Ham-F10 com $10 \%$ de SFB contendo $10^{5}$ células/ml foi inoculada em cada poço de placas de cultura de células com 24 poços $\left(\right.$ Corning $\left.^{\circledR}\right)$. As placas foram incubadas a $37^{\circ} \mathrm{C}$ por 12 horas. Após este período de incubação $0,1 \mathrm{ml}$ de $\mathrm{F}_{6} \mathrm{H}_{8}$ foi adicionado sobre o tapete celular. Como controle de peso, foram utilizadas lamínulas de vidro, fazendo a compressão mecânica proporcional ao peso e área dos $0,1 \mathrm{ml}$ de $\mathrm{F}_{6} \mathrm{H}_{8}$ utilizado, porém inertes no que tange a toxicidade. Como controle negativo utilizou-se as células cultivadas em meio de cultura na ausência de qualquer outro tratamento. Como controle positivo de citotoxicidade, utilizou-se adesivos de silicone (Rhodiastic $^{\circledR}$ ), com peso e área proporcional à ocupada pelo $\mathrm{F}_{6} \mathrm{H}_{8}$. As amostras foram colhidas fixadas e coradas, após um período de doze horas da adição de $\mathrm{F}_{6} \mathrm{H}_{8}$, momento em que os achados foram mais significativos e expressivos das transformações metabólicas e estruturais das células. Essas amostras foram então processadas para análise imunocitoquímica.

\section{Análise imunocitoquímica}

Após 12 h de contato com o $\mathrm{F}_{6} \mathrm{H}_{8}$, ou com seus respectivos controles. Após $12 \mathrm{~h}$ de incubação o meio de cultivo foi retirado e as placas foram lavadas com salina $0,9 \%$ em tampão fosfato
(PBS) a $37^{\circ} \mathrm{C}$. O material foi fixado em solução de Karnovsky modificada (paraformaldeído 4\%/glutaraldeído 0,2\%, em tampão fosfato $0,1 \mathrm{M}, \mathrm{pH} 7,4$ ) com Triton X 100 a $0,2 \%$ durante 30 minutos, lavadas com $\mathrm{PBS}$ a $37^{\circ} \mathrm{C}$ e incubadas com PBS mais albumina sérica bovina (BSA, Sigma) a $1 \%$ durante uma hora a $4^{\circ} \mathrm{C}$. O material foi tratado com anticorpo monoclonal primário anti-actina (Sigma, clone AL - 40, prod. número A-4.700, Lote 0744826) diluído 1:200 e após diluído 1:40 em PBS contendo BSA a $1 \%$ durante $18 \mathrm{~h}$ a $4^{\circ} \mathrm{C}$ em câmara úmida. Após lavagem com PBS mais BSA a $1 \%$ o material foi incubado por uma hora com anticorpo secundário antimouse IgG conjugado com FITC (Sigma) diluído 1:128 em PBS mais BSA a 1\%, lavado com PBS mais BSA e montado em lâmina com Vectashield ${ }^{\circledR}$ e vedação com esmalte. A observação foi efetuada em microscópio invertido Olimpus IX-50 usando filtros para fluorescência e fotografado com filme Kodak ${ }^{\circledR}$ ISO 400.

\section{Microscopia eletrônica de varredura (MEV)}

O procedimento básico de ensaio em microscopia eletrônica, com as condições de cultura e controles utilizados foram os mesmo descritos anteriormente. As células foram fixadas em Paraformaldeído 4\%/Glutaraldeído 2,5\% (Merck KgaA, Darmstadt, Germany) em tampão fosfato 0,1 M, pH 7,4 por duas horas, então lavado em tampão fosfato, pós-fixado em tetróxido de ósmio 1\% (Sigma) por 15 minutos, e desidratado em uma série de etanol. Após esse procedimento, as amostras foram desidratadas em ponto crítico (Balzers CPDO030) e recobertas com ouro em sputter (Balzers 050). As células foram observadas em microscópio eletrônico de varredura modelo JEOL JSM-5800 LV.

\section{RESULTADOS}

\section{Teste de citotoxicidade indireta}

$\mathrm{O}$ resultado da leitura da placa, não mostrou diferenças significativas do $\mathrm{F}_{6} \mathrm{H}_{8}$ sobre o crescimento celular nas diferentes condições de cultura empregadas. Desta forma, nossos resultados indicam que o $\mathrm{F}_{6} \mathrm{H}_{8}$ não libera nenhuma substância tóxica solúvel para o meio de cultura. Esses resultados podem ser observados na figura 1.

\section{Análise imunocitoquímica}

Pode-se observar nos controles negativos do experimento, células formando um tapete semiconfluente e que apresentavam seus filamentos de actina homogeneamente distribuídos e ocupando todo o citoplasma (Figura 2A). Na figura 2B observase detalhe da figura anterior. Na figura $2 \mathrm{C}$, são apresentadas as células após 12 horas do efeito do peso das lamínulas com equivalência ao peso do $\mathrm{F}_{6} \mathrm{H}_{8}$. Observaram-se alterações na morfologia celular com retração citoplasmática, formação de prolongamentos finos e longos, com consequiente acúmulo de actina próximo aos limites celulares. Detalhe da amostra anterior é mostrado na figura 2D. Nas células sob a ação tóxica do 


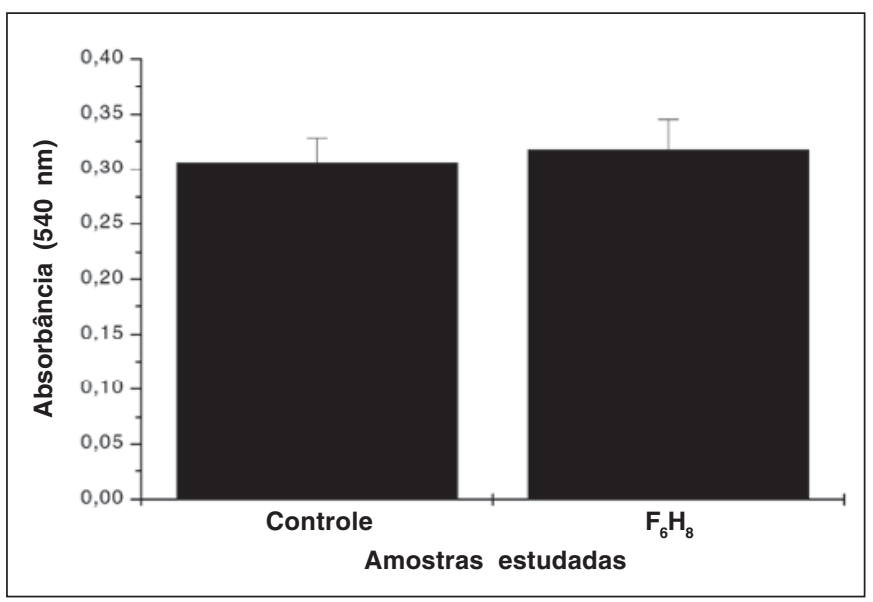

Figura 1 - Análise da citotoxicidade indireta do $\mathrm{F}_{6} \mathrm{H}_{\mathrm{g}}$. As amostras cultivadas com estrato de $\mathrm{F}_{6} \mathrm{H}_{8}$ foram consideradas nẫo significativamente diferentes (nível de 0,05 ) em relação aos controles utilizados $\left(\mathrm{F}_{6} \mathrm{H}_{8}\right.$ : perfluorohexiloctane)

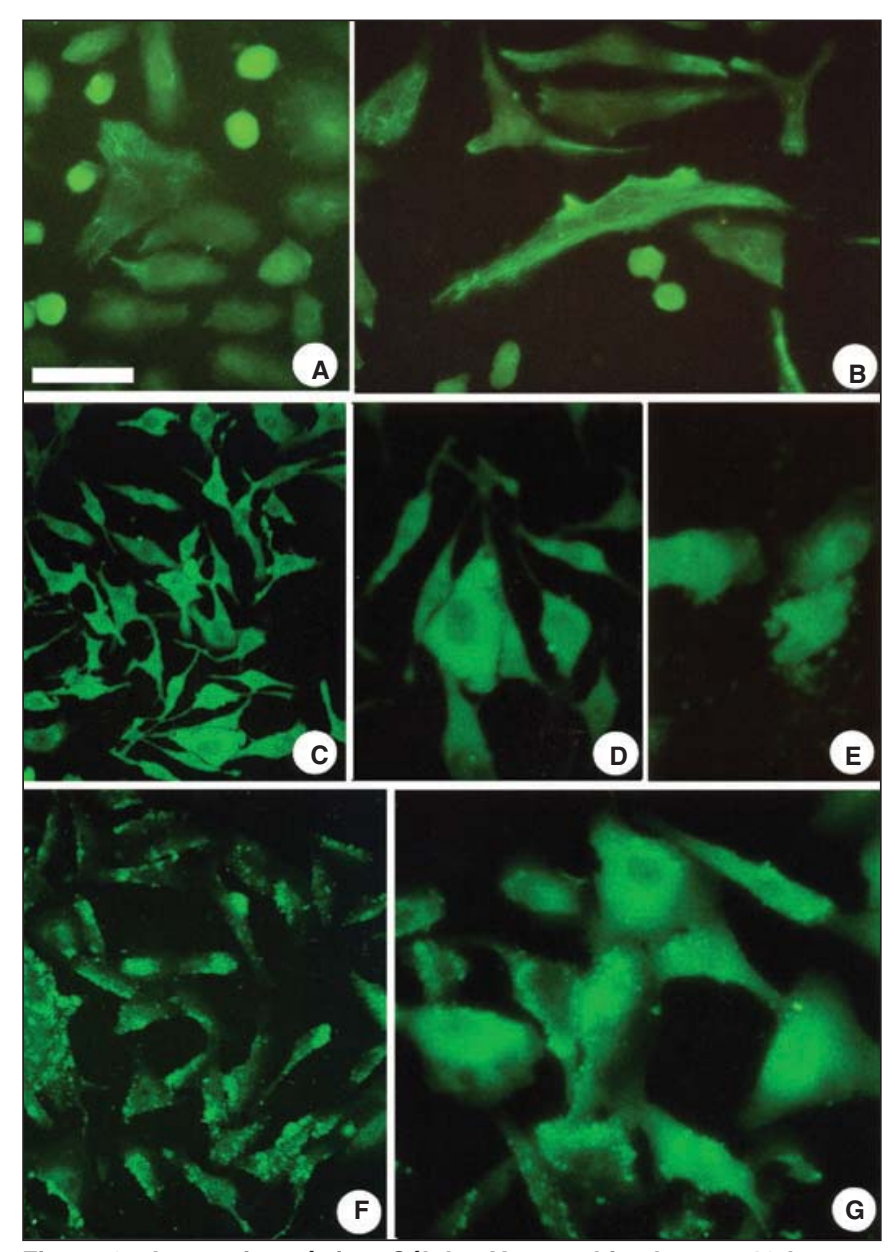

Figura 2 - Imunocitoquímica: Células Vero, cultivadas por 12 horas e incubadas com anticorpo monocloral anti-actina; A e B: controle negativo do experimento (sem a ação de efeito químico ou mecânico); C e D: Células após 12 horas do efeito do peso das lamínulas com equivalência ao peso de $\mathrm{F}_{6} \mathrm{H}_{8}$; E: Células sem ação tóxica do silicone com peso equivalente ao do $\mathrm{F}_{6} \mathrm{H}_{8} ; \mathrm{F}$ e G: Células sob o efeito compressivo do $\mathrm{F}_{6} \mathrm{H}_{8}$. Barra de aumento $=5 \mu \mathrm{m}(A, C$ e E) ou $50 \mu \mathrm{m}(B, D$ e $F)$ silicone observaram-se células com morfologia irregular, ou fragmentada, com retração citoplasmática e ausência de prolongamentos (Figura 2E). Quando cultivadas em meio de cultura em contato direto com o $\mathrm{F}_{6} \mathrm{H}_{8}$, as células apresentaram alteração na morfologia, regiões de acúmulo de actina com distribuição pontual (Figuras 2F e 2G).

\section{Microscopia eletrônica de varredura}

Nas células que cresceram sobre as lamínulas de vidro sem qualquer tratamento observou-se tapete celular semiconfluente composto por células bastante achatadas. Algumas vesículas podem ser observadas na superfície dessas células (Figura 3A e 3B). Após 12 horas do efeito do peso das lamínulas com equivalência ao peso de $\mathrm{F}_{6} \mathrm{H}_{8}$, visualizaram-se células retraídas, com morfologia bastante irregular, apresentando prolongamentos finos e longos conectando uma célula a outra (Figura 3C). Foi observado ainda, um maior aumento de vesículas e/ou microvilosidades na superfície das células (Figura 3D). Nas células cultivadas em meio de cultura em contato direto com o $\mathrm{F}_{6} \mathrm{H}_{8}$ encontramos retração citoplasmática e projeções de alguns prolongamentos (Figura 3E e 3F).

\section{DISCUSSÃO}

Os perfluorocarbonos apresentam propriedades físicas similares entre si, como um alto peso específico (maior peso em relação ao mesmo volume), imiscibilidade com a água e sangue $^{(23)}$. Alguns autores, avaliando o uso de PFCLs como substitutos do vítreo de longo prazo, concluíram que mesmo estando altamente purificados, eles são tóxicos à reti$\mathrm{na}^{(12,14,24,25)}$. Por outro lado, autores descrevem em seus experimentos que a retenção no vítreo de um pequeno volume de perfluorocarbono líquido depois de seu uso intra-operatório não induz resposta tóxica ${ }^{(11,23,26-27)}$. Liang e Peyman ${ }^{(8)}$ e Mertens et $\mathrm{al}^{(1)}$ consideram que as alterações celulares encontradas seriam decorrentes de um efeito físico, e que uma eventual toxicidade química seria conseqüência de impurezas durante a formulação do produto. Devido à limitação do uso dos PFCLs como substituto do vítreo de longo prazo $^{(28)}$ - decorrente do efeito compressivo muito intenso e do discutível efeito tóxico - novos produtos foram lançados no mercado com este objetivo, entre eles o $\mathrm{F}_{6} \mathrm{H}_{8}$.

A avaliação das alterações celulares sob efeito do $\mathrm{F}_{6} \mathrm{H}_{8}$ foi realizada para possibilitar uma comparação dos achados estruturais ocasionados por este SFA, atuando diretamente sobre o tapete celular versus as alterações ocasionadas por um controle, com peso e área proporcional, comprovadamente não tóxico pelo contato.

Embora $\mathrm{o}_{6} \mathrm{H}_{8}$ tenha sido testado quanto a sua toxicidade em cultura de células e não tenha demonstrado inibir a proliferação celular ${ }^{(29)}$, este produto ainda não foi avaliado tendo como parâmetro um efeito compressivo inerte. Isto permitiu uma observação paralela dos achados encontrados no experimento. $\mathrm{O}$ estudo das alterações celulares sob a ação destas 


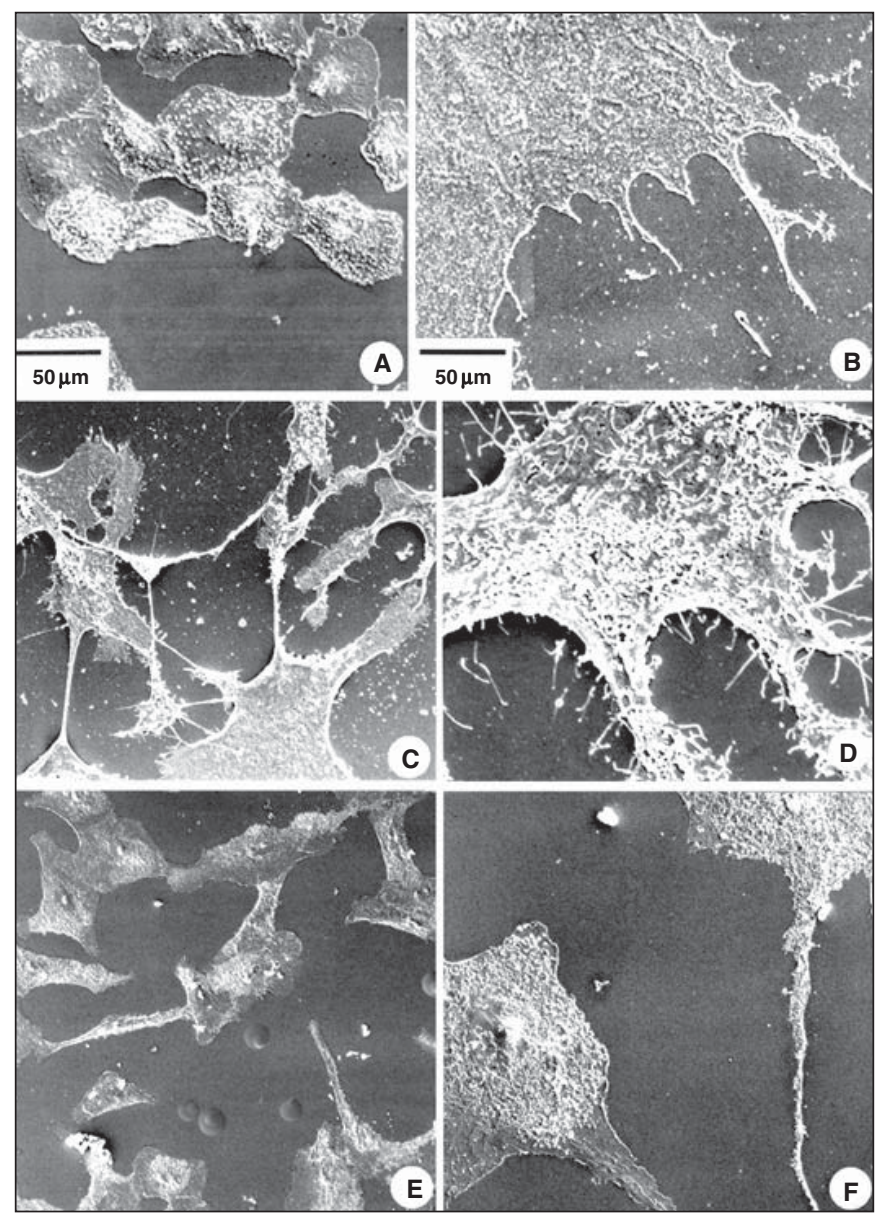

Figura 3 - Microscopia eletrônica de varredura das células Vero submetidas as diferentes condições experimentais: A e B: controle negativo do experimento (sem a ação de efeito químico ou mecânico); C e D: Células após 12 horas do efeito do peso das lamínulas com equivalência ao peso de $\mathrm{F}_{8} \mathrm{H}_{8}$; E e F: Células sob o efeito compressivo do $\mathrm{F}_{8} \mathrm{H}_{8}$. Barra de aumento $=5 \mu \mathrm{m}(\mathrm{A}, \mathrm{C}$ e E) ou $50 \mu \mathrm{m}(\mathrm{B}, \mathrm{D}$ e F)

substâncias é importante pela necessidade de se ter um produto que possa ser mantido dentro do olho no pós-operatório, por um período maior de tempo, consolidando o resultado de uma cirurgia bem sucedida, para que a retina recém reaplicada assim permaneça.

$\mathrm{O}$ teste de citotoxidade indireta mostra claramente que o $\mathrm{F}_{6} \mathrm{H}_{8}$ não elimina substâncias que possam ser deletérias à célula. Estes achados condizem com os dados obtidos por Meinert e Roy com diferentes culturas de células ${ }^{(30)}$. Desta forma podemos afirmar de forma conclusiva que o $\mathrm{F}_{6} \mathrm{H}_{8}$ não apresenta toxicidade indireta. As alterações são, portanto, contato-dependentes e observadas após um determinado período de exposição. Durante este experimento testes realizados com tempos de contato mais curtos, entre as células com os diferentes pesos e as substâncias, mostraram alterações menos marcadas enquanto que tempos de contato maiores levavam a destruição celular que impedia qualquer análise (dados não mostrados).

Observou-se que as alterações morfológicas evidenciadas pela imunocitoquímica nas células que estiveram sob o efeito do $\mathrm{F}_{6} \mathrm{H}_{8}$ são similares aos danos promovidos pelo controle de peso e marcadamente menores que as encontradas nas células que cresceram em contato com a ação tóxica do silicone. Isso sugere que $\mathrm{o}_{6} \mathrm{H}_{8}$ não apresenta comprometimento de natureza tóxica direta.

Danos estruturais também puderam ser observados com detalhe na microscopia eletrônica de varredura (MEV), onde as alterações foram visualizadas com maior resolução. A MEV mostrou retração citoplasmática leve e um aumento das vesículas na superfície celular nas amostras submetidas ao controle peso. Por outro lado, ocorreu uma discreta diminuição no número e na espessura dos prolongamentos das células sob efeito do $\mathrm{F}_{6} \mathrm{H}_{8}$. Em ambos os casos encontraram-se células irregulares e com prolongamentos partindo do citoplasma.

A análise conjunta dos resultados obtidos através da citotoxicidade direta e indireta aponta para efeitos nas células limitados apenas à área em contato com o $\mathrm{F}_{6} \mathrm{H}_{8}$ e estão de acordo com trabalhos previamente reportados em cirurgias experimentais em animais, que observaram alterações apenas nas partes dos tecidos em contato com a droga $\mathrm{a}^{(19)}$.

Baseados em nossos resultados, pode-se considerar que o efeito mecânico do $\mathrm{F}_{6} \mathrm{H}_{8}$ e do peso equivalente ocasionado à camada celular tenham alterado o funcionamento da mesma, impedindo as trocas metabólicas normais entre as células e o meio de cultura. Esta condição permaneceu constante para todas as células durante o experimento. $O$ fato de não se encontrarem, no entanto, diferenças marcantes nos resultados, sugerem que o $\mathrm{F}_{6} \mathrm{H}_{8}$ não apresenta outro mecanismo de ação, que não o efeito compressivo, para as alterações encontradas. Esses dados então em acordo com outros relatos previamente publicados ${ }^{(29)}$.

Em conjunto, estes resultados apontam para a interpretação de que as alterações estruturais provocadas pelo $\mathrm{F}_{6} \mathrm{H}_{8} \mathrm{em}$ olhos após cirurgias em animais de experimentação seriam principalmente em decorrência da força mecânica do mesmo, exercida sobre os tecidos no qual estão em contato e tempodependente. Não existindo uma provável ação tóxica dessas substâncias quando em contato com as células, em acordo com os relatos publicados por Zeana et $\mathrm{al}^{(19)}$.

A efetividade do $\mathrm{F}_{6} \mathrm{H}_{8}$ como agente para tamponar as rupturas da retina inferior e mantê-la aplicada a seu leito ainda necessita de novas investigações. A provável ausência de toxicidade e seu menor peso sugerem que se tente usá-lo como substituto do vítreo, embora os possíveis efeitos secundários e o tempo preciso de uso, sem que ocorram alterações celulares, ainda precise ser definido.

\section{ABSTRACT}

Purpose: Perfluorocarbon liquids (PFCLs) are used in vitreoretinal surgery. PFCLs may cause inflammatory reactions, cellular injury and destruction of the normal retinal architecture. In order to avoid these effects, semifluorinated alkanes 
(SFA) were developed. We assessed the potential use of an SFA known as perfluorohexiloctano $\left(\mathrm{F}_{6} \mathrm{H}_{8}\right)$ as long-term vitreous replacement under controlled cell culture conditions. Methods: We analyzed indirect cytotoxicity, where the cells only come into contact with soluble elements that can be eliminated by perfluorohexiloctano. We therefore analyzed direct toxicity (contact toxicity) of perfluorohexiloctano by means of scanning electronic microscopy and immunocytochemistry reagents for actin. Cells embedded in a treatmentfree culture medium were used as control, a positive control for toxicity with an undeniably toxic effect on cells, and a weight control that produced a mechanical compression similar to the amount of perfluorohexiloctano used in the experiment. Results: The indirect cytotoxicity test showed that $\mathrm{F}_{6} \mathrm{H}_{8}$ did not affect cell growth. Our direct toxicity tests showed that cellular alterations caused by perfluorohexiloctano were similar to those produced by the weight control and different from toxicity control. Conclusions: Perfluorohexiloctano does not present indirect toxicity and this product has a compressive rather than a toxic effect on cultured cells.

Keywords: Fluorocarbones/toxicity; Cell culture; Ophthalmologic surgical procedures

\section{REFERÊNCIAS}

1. Mertens S, Bednarz J, Richard G, Engelmann K. Effect of perfluorodecalin on human retinal pigment epithelium and human corneal endothelium in vitro. Graefes Arch Cli Exp Ophthalmol. 2000;238(2):181-5.

2. Mathis A, Pagot V, Gazagne C, Malecaze F. Giant retinal tears. Surgical techniques and results using perfluorodecalin and silicone oil tamponade. Retina. 1992; 12(3 Suppl):S7-10.

3. Chang S, Reppucci V, Zimmerman NJ, Heinemann MH, Coleman DJ. Perfluorocarbon liquids in the management of traumatic retinal detachments. Ophthalmology. 1989;96(6):785-92.

4. Glaser BM, Carter JB, Kuppermann BD, Michels RG. Perfluoro-octane in the treatment of giant retinal tears with proliferative vitreoretinopathy. Ophthalmology. 1991;98(11):1613-21.

5. Chang S, Ozmert E, Zimmerman NJ. Intraoperative perfluorocarbon liquids in the management of proliferative vitreoretinopathy. Am J Ophthalmol. 1988; 106(6):668-74.

6. Moreira Junior CA, Uscocovich CE, Moreira AT. Experimental studies with perfluoro-octane for hemostasis during vitreoretinal surgery. Retina. 1997;17(6): 530-4.

7. Sparrow JR, Jayakumar A, Berrocal M, Ozmert E, Chang S. Experimental studies of the combined use of vitreous substitutes of high and low specific gravity. Retina. 1992;12(2):134-40.

8. Liang C, Peyman GA. Tolerance of extended-term vitreous replacement with perfluoro-n-octane and perfluoroperhydrophenanthrene mixture (phenoctane). Retina. 1999;19(3):230-7.
9. Loewenstein A, Humayun MS, de Juan E Jr, Campochiaro PA, Haller JA Perfluoroperhydrophenanthrene versus perfluoro- $n$-octane in vitreoretinal surgery. Ophthalmology. 2000;107(6):1078-82.

10. Estacia P, Rodrigues Jr AS, Moreira PL, Genari SC. The cytotoxicity in vero cells of a perfluorocarbon used in vitreoretinal surgery. Braz J Morphol Sci. 2000;19(2):41-7.

11. Chang S, Sparrow J R, Iwamoto T, Gershbein A, Ross R, Ortiz R. Experimental studies of tolerance to intravitreal perfluoro-n-octane liquid. Retina. 1991;11 (4):367-74.

12. Meller D, Augustin AJ, Spitznas M, Lutz J, Meller K. Effect of different perfluorochemicals on dorsal root ganglion cells in vitro. Graefes Arch Clin Exp Ophthalmol. 1998;236(3):182-7.

13. Winter M, Winter C, Wiechens B. Quantification of intraocular retained perfluorodecalin after macroscopic complete removal. Graefes Arch Clin Exp Ophthalmol. 1999;237(2):153-6.

14. Velikay M, Wedrich A, Stolba U, Datlinger P, Li Y, Binder S. Experimental long-term vitreous replacement with purified and nonpurified perfluorodecalin. Am J Ophthalmol. 1993;116(5):565-70.

15. Kirchhof B. Fluorocarbones in vitreoretinal surgery. Ophtalmo-Chirurgie 1999; 11:153-8

16. Singer H. New studies further define role of PFCLs in vitreoretinal surgery. Ocular Surg News. 1999;17(Feb):50.

17. Langefeld S, Kirchhof B, Meinert H, Roy T, Aretz A, Schrage NF. A new way of removing silicone oil from the surface of silicone intraocular lenses. Graefes Arch Clin Exp Ophthalmol. 1999;237(3):201-6.

18. Wong D, Lois N Perfluorocarbons and semifluorinated alkanes. Semin Ophthalmol. 2000;15(1):25-35. Review.

19. Zeana D, Becker J, Kuckelkorn R, Kirchhof B. Perfluorohexiloctano as long-term vitreous tamponade in the experimental animal. Experimental perfluorohexiloctano substitution. Int Ophthalmol. 1999;23(1):17-24.

20. Kirchhof B, Wong D, Van Meurs J, Hilgers RD, Macek M, Lois N, Schrage NF. Use of perfluorohexiloctano as a long-term internal tamponade agent in complicated retinal detachment surgery. Am J Ophthalmol. 2002;133(1):95-101.

21. Stefaniotou MI, Aspiotis MV, Kitsos GD, Kalogeropoulos CD, Asproudis IC, Psilas KG. Our experience with perfluorohexiloctano (F6H8) as a temporary endotamponade in vitreoretinal surgery. Eur J Ophthalmol. 2002;12(6): 518-22

22. Vote B, Wheen L, Cluroe A, Teoh H, McGeorge A. Further evidence for proinflammatory nature of perfluorohexiloctano in the eye. Clin Experiment Ophthalmol. 2003;31(5):408-14.

23. ISO 10993-1 Biological evaluation of medical devices - Part. 5. - Tests for cytotoxicity: "in vitro" methods. 1992.

24. Murakami N, Fukuchi S, Takeuchi K, Hori T, Shibamoto S, Ito F. Antagonistic regulation of cell migration by epidermal growth factor and glucocorticoid in human gastric carcinoma cells. J Cell Physiol. 1998;176(1):127-37.

25. Peyman GA, Schulman JA, Sullivan B. Perfluorocarbon liquids in ophthalmology. Surv Ophthalmol. 1995;39(5):375-95. Review.

26. Chang S. Low viscosity liquid fluorochemicals in vitreous surgery. Am J Ophthalmol. 1987;103(1):38-43.

27. Eckardt C, Nicolai U, Winter M, Knop E. Experimental intraocular tolerance to liquid perfluorooctane and perfluoropolyether. Retina. 1991;11(4):375-84.

28. Stolba U, Krepler K, Pflug R, Velikay M, Wedrich A, Binder S. Experimental vitreous and aqueous replacement with perfluorophenanthrene. Retina 1997; 17(2):146-53

29. Green K, Slagle T, Chaknis MJ, Cheeks L, Chang S. Perfluorocarbon effects on rabbit blood-retinal barrier permeability. Ophthalmic Res. 1993;25(3):186-91.

30. Meinert H, Roy T. Semifluorinated alkanes - a new class of compounds with outstanding properties for use in ophthalmology. Eur J Ophthalmol. 2000; 10(3):189-97. 